\title{
Vascular Stenosis
}

National Cancer Institute

\section{Source}

National Cancer Institute. Vascular Stenosis. NCI Thesaurus. Code C115152.

Narrowing of the lumen of an artery or vein. 